\title{
Academic Integrity in the Age of COVID-19: the Case of Tertiary Education \\ System in Greece
}

\section{Keywords}

Academic Integrity; Tertiary Education System; Covid-19; Online Education; Contract cheating

The COVID-19 pandemic brought about a violent readjustment of established practice in several areas. The changes in university education have been sweeping; the academic community as a whole was forced to adjust to a hybrid mode of education, with particular weight given to remote education (Reynolds \& Chu, 2020).

Academic dishonesty is defined as "intentionally unethical behaviour in an academic environment" (Muhammad et al., 2020). It involves inappropriate behaviour by means of which students attempt to gain an advantage for themselves or their friends in the academic community (Grira \& Jaeck, 2019). A recently published meta-analysis on the issue of academic dishonesty (Krou et al., 2020) showed that academic dishonesty was negatively associated with classroom mastery goal structure, individual mastery approach goals, intrinsic motivation, self-efficacy, utility value, and internal locus of control, but was positively linked with amotivation and extrinsic goal orientation. Furthermore, according to this meta-analysis, two fundamental categories of academic dishonesty are recognized in literature: plagiarism (e.g. integrating existing material into one's work without citing the original author, presenting a work written by a third party as one's own, etc.) and cheating (e.g. receiving answers to exam questions from some other student who has finished taking the exam, collaborating with others to write a term paper without having been given permission to do so, cheating during an exam, using external aids without permission during the exam, etc.).

It is often stated in older literature that the availability of new technological means does not affect the percentage of students who resort to cheating; however, more recent studies reveal that academic dishonesty constitutes a well known and widespread occurrence that has recently seen an increase in intensity (Birks et al., 2020; Harper et al., 2020). Furthermore, it is important to 
note that academic dishonesty is a multifactorial as well as an supracultural global phenomenon (Bashir \& Bala, 2018; Ives et al., 2017).

Remote university education had constituted a good practice for many years; because of its inherent limitations, however, it had not been established as a practice in the teaching of a number of academic subjects. The pandemic forced the application of remote education in subjects where there had been no previous experience hitherto with it.

A serious issue one is faced with when holding remote exams (in remote academic programmes) is the variety of technological means which can facilitate unethical behaviour, e.g. exchanging information online, consulting with friends, and easily copying and integrating existing content (PeytchevaForsyth et al., 2018; Sarwar et al., 2018).

Among the consequences of this forced readjustment has been an increase in the employment of cheating methods. Consequently, this led to a heated debate within the academic community concerning the matter of academic integrity. One of the more serious problems is that of online assessment, given that the way exams are held in their majority provides students with the possibility of using various technological means, thus facilitating unethical behaviour on their part.

Recent studies (Amzalag et al. 2021) on academic dishonesty point out significant differences between student and teacher perceptions concerning attitudes toward online exams and the reasons behind dishonest behaviour. In particular, it showed a lack of mutual trust between students and teaching staff on the issue of academic dishonesty - a deep mistrust which is likely to persist even after the COVID-19 crisis has abated.

Both in the press and in literature there are constant reports of a sharp increase in cases of cheating and academic dishonesty. In Inha University's School of Medicine in Incheon, in South Korea, approximately 90 students were caught cheating, constituting $83 \%$ of first and second year students in the School of Medicine (https://abcnews.go.com/International/med-school-students-southkorea-caught-cheating-online/story?id=71043491); in the USA, the credibility of the Advanced Placement (AP) exams took a hit following a great number of reports of instances of academic dishonesty, including the use of Discord servers for common use of answers to exam questions (https://www.teenvogue.com/story/2020-ap-exams-cheating).

In Greece, during the winter semester exam period of 2020, faculty members in various Universities were already aware of this practice, announcing countermeasures and promising more complex exam questions in order to 
discourage cheating. At the institutional level, the Statistics Section of the Department of Mathematics at the University of Athens called for a postponement of the exams. In a similar vein, the School of Economics at the University of Athens decided to hold mathematics exams at the very end of the exam period, while it is still undecided whether the exams will be held for all students or solely for those pending graduation (R. Harper et al, 2021). This is due to the fact that more than 1,200 students have applied for the exam; this number is unprecedentedly high, and faculty members are wary that students have devised new ways of cheating (P. Dawson et al, 2020).

The Greek government and the Ministry of Education has also taken measures. In January 2021, a new disciplinary action law was submitted in a bill proposed by the Ministry of Education concerning changes in higher education. The bill contained provisions for disciplinary action in instances of cheating and damages to university property. Penalties range from exclusion from exams and suspension of student status to permanent expulsion and withdrawal of student status (R. Comas-Forgas et al, 2020).

\section{FINDINGS AND DISCUSSION}

Against this situational analysis, this study will at first present findings from a survey conducted among faculty members of Greek universities to assess their views on the issue of cheating in exams, both prior to and in the wake of the COVID-19 pandemic.

Survey findings are telling, demonstrating the difficulties faced by faculty members regardless of subject. The survey outlines the means employed by students who attempted to cheat in the exams. Furthermore, the survey illustrates the various types of cheating in addition to the ways in which informal institutions (namely providers of private tutoring for students, known in Greek as "frontistiria") provided contract cheating services to students - and how the academic community attempted to deal with this practice.

The topic examined in this context, although it focuses on findings from data analysis from a specific area, is actually relevant to academic settings in many other countries (Khomami, 2017; Marsh,2017). The research presented has in its focus the analysis of breaches of academic integrity during exams from the perspective of faculty. The main research objectives are listed below:

1. Collect data relevant to breaches of academic integrity in higher education in Greece during the pandemic period

2. Identify possible factors that push students to breach academic integrity 
3. Compare finding in relation to other similar surveys

4. Assess teachers' views on the issue of cheating during e-learning modules.

5. Attempt to establish whether there was an increase in cases of cheating in the exams during the pandemic.

Our methodological approach is based on qualitative research (qualitative and non-numerical data was collected) as well as quantitative research (quantitative or numerical data was collected). Therefore, for this study, the methodology chosen is that of the mixed method - we designed a survey that would collect data for both quantitative and qualitative study. The survey was conducted based on a questionnaire to systematically investigate the characteristics, opinions and the relationship between the variables of the questionnaire. The sampling method chosen is group sampling.

Data collection was conducted through a survey which took place online (using Google forms) from April $1^{\text {st }}$ to May $31^{\text {st }}$ 2021. It was targeting full-time and adjunct faculty at Universities, Technical Universities and other tertiary education institutes in Greece. The sampling method chosen was convenience sampling, and a total of 44 valid and complete questionnaires were collected from nine different Universities in Greece. Participating Universities include four from major, metropolitan areas of Greece, while the remaining represent the rest of the mainland and islands of Greece.

Responders spanned all academic rankings, namely, $16.7 \%$ of them are at the rank of "Professor"; 9.5\% are Associate Professors; $16.7 \%$ are at the rank of "Assistant Professor" (tenured), 9.5\% are at the rank of "Lecturer," and the remaining $14.3 \%$ have either part-time tasks or special teaching duties. Faculty ranks are also co-related with the faculty's time of employment at the University; employment time ranges from 6 years for junior faculty to 25 years for senior faculty.

In Greece, University faculty might also serve as Adjunct Faculty at the Hellenic Open University (HOU). The Hellenic Open University is the only University in Greece which by law can offer online programmes. As a result, Adjunct Faculty at HOU have experience in pedagogy, ICT tools and platforms for distance learning. Therefore, it is interesting to examine the perceptions of Adjunct Faculty at HOU because they were primarily the ones who had experience with the online delivery of courses, before the pandemic. More specifically, $9.5 \%$ of the respondents also teach at HOU. Additionally, when 
faculty were asked a question regarding the mode of delivery for their courses, 92.9\% answered that they hold face-to-face lectures, $7.1 \%$ were involved in Distance Learning, and $2.4 \%$ follow a blended learning approach.

Faculty have diverse scientific backgrounds; $16.7 \%$ of them are in "Healthcare Sciences", 16.7\% in "Social Sciences", 11.9\% in "Engineering", $9.5 \%$ in "Information Technology", 7.1\% in "Economics", 4.8\% in "Physics", 4.8\% in "Civil Engineering", 4.8\% in "Biology", 2.4\% in "Mathematics", 2.4\% in "Environmental Science", 2.4\% in "Biomedical Technology", 2.4\% in "Agronomy", 2.4\% in "Statistics/Research Methodology", 2.4\% in "Business Management", 2.4\% in "Electrical Engineering", and 2.4\% in "Graphic Arts". The majority of faculty (92.9\%) teach undergraduate courses, while $66.8 \%$ of them also teach at a postgraduate level; only a small percentage $(2.4 \%)$ were affiliated with the "Centre for Education and Lifelong Learning."

With regards to topics relevant to academic integrity, it appears that plagiarism is a major concern among Greek faculty; other breaches of academic integrity seem to be lower in the agenda. Almost three-quarters of the faculty are aware of text similarity software, whereas $45.2 \%$ of them admitted that they were not aware of the term "ghostwriting", and $42.9 \%$ of them were not aware of the term "contract cheating". It is interesting to see how they deter breaches of academic integrity. Almost a third of faculty (28.6\%) have been using antiplagiarism software both at undergraduate and postgraduate levels, while $14.3 \%$ use it exclusively for their postgraduate courses. With regards to contract cheating/ghostwriting, almost three-quarters (76.2\%) of the participating faculty were aware of offers from third parties to undertake written assignments of students but less so (50\%) with regards to offers of undertaking examinations in lieu of the students themselves. Faculty perception with regards to these two breaches of academic integrity was that they were more extensive during the pandemic: $54.8 \%$ for contract cheating/ghost writing and $87.5 \%$ for unlawful impersonation during written examinations

Related to the above, more faculty used text-similarity software to detect and deter plagiarism during the pandemic; $47.6 \%$ used it both at an undergraduate and a postgraduate level compared to $28.6 \%$ before the pandemic, and $21.4 \%$ compared to $14.3 \%$ before the pandemic used this tool for postgraduate courses. It is noted that those who started using text-similarity software during 
the pandemic overwhelmingly respond that they will continue using it in the future.

With regards to policies regarding academic integrity endorsed by Greek Universities, it appears that there is room for improvement either for their adoption by more institutions or for awareness-raising activities among faculty on the existence of those policies. Percentages among faculty being aware of the existence of relevant policies range from $38.6 \%$ for policies on plagiarism to $13.6 \%$ for policies on ghost-writing.

Figure 1 presents the assessment of participating faculty regarding the sufficiency of software detecting text similarities and, thus, deterring plagiarism. The answers show that faculty appreciate the support provided by the software tool. However, very few recognize this software as an absolutely efficient tool.

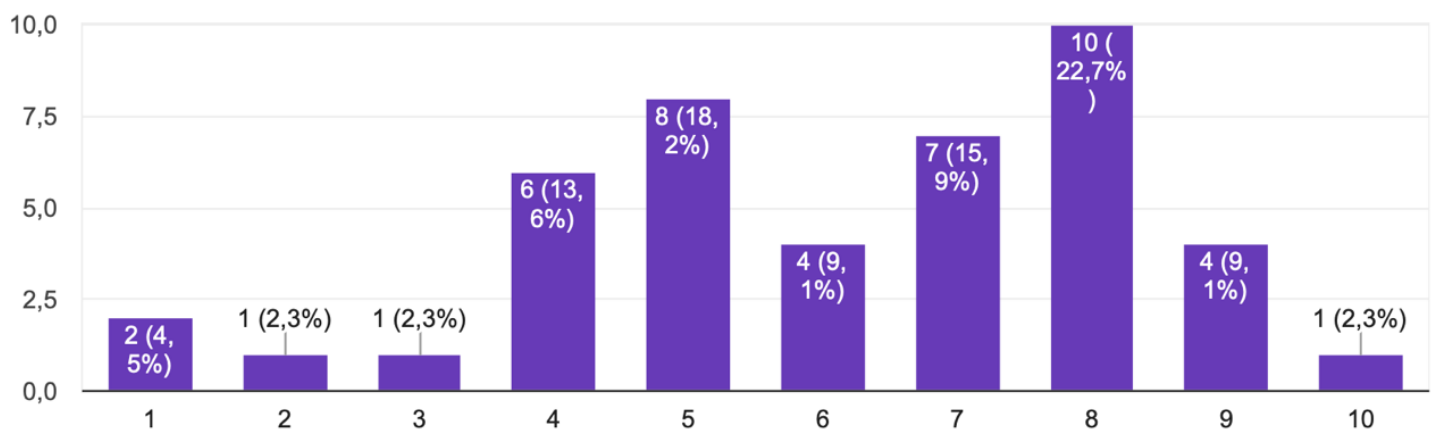

Figure 1. Faculty percentages for levels of anti-plagiarism software's efficiency;

\section{(Range: 1-10, with 1 being inefficient and 10 being absolutely efficient)}

When we asked faculty how students become aware of the gravity and consequences of breaches of academic integrity, the majority of faculty (61.9\%) responded that students should be informed by their instructors. Some other approaches were also noted: 40.5\% answered "through the University/School/Department website"; 40.5\% "through the syllabus"; $35.7 \%$ "through them being aware of the existence of plagiarism detection software"; $19 \%$ "through announcements available at the online classes of each subject"; $7.1 \%$ "through official information leaflets". It is noted that only $38.1 \%$ reported that there is a systematically organized activity to promote academic integrity through a dedicated lecture at the beginning of the semester, and $2.4 \%$ of 
faculty failed to report on the measures used to communicate the importance of academic integrity to students.

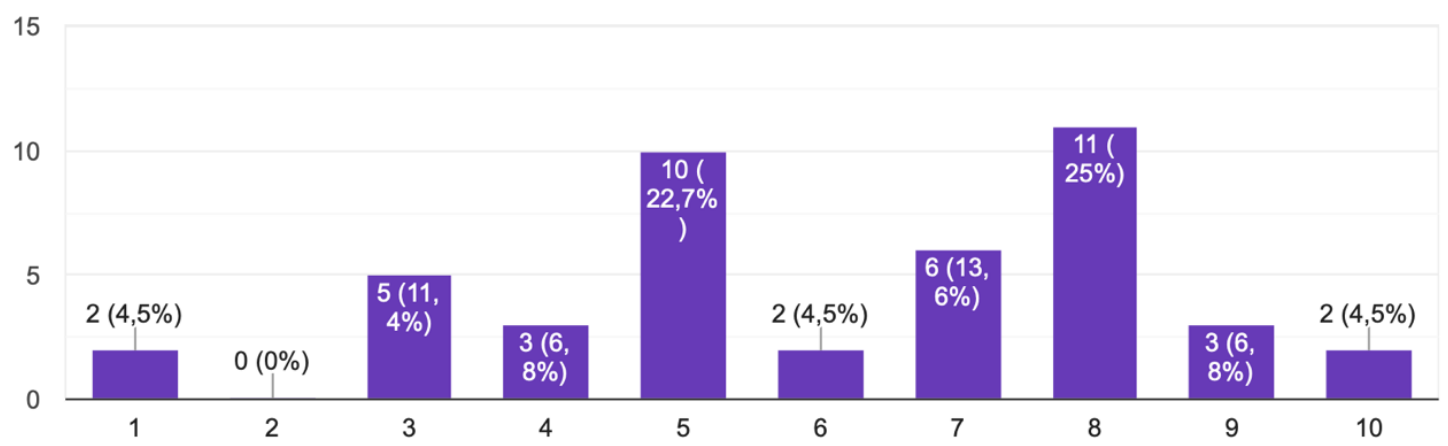

Figure 2. Faculty percentages for levels of policies efficiency;

(Range: 1-10, with 1 being inefficient and 10 being absolutely efficient)

It is also interesting to examine how faculty view the efficiency of policies and procedures institutionalized at their universities. As shown in Figure 2, opinions vary greatly. At this point, further analysis is required to see how results come out for each University. The overall picture, however, makes it obvious that policies and procedures may be further improved upon, based on the assessment of participating faculty.

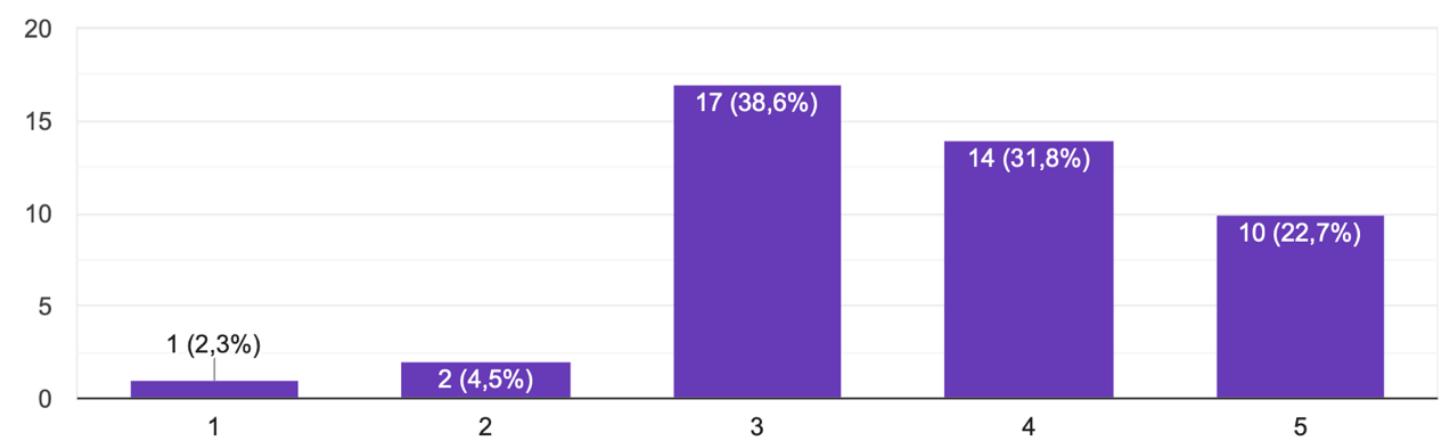

Figure 3. Information regarding University policy on plagiarism and the penalties thereof is available to students.

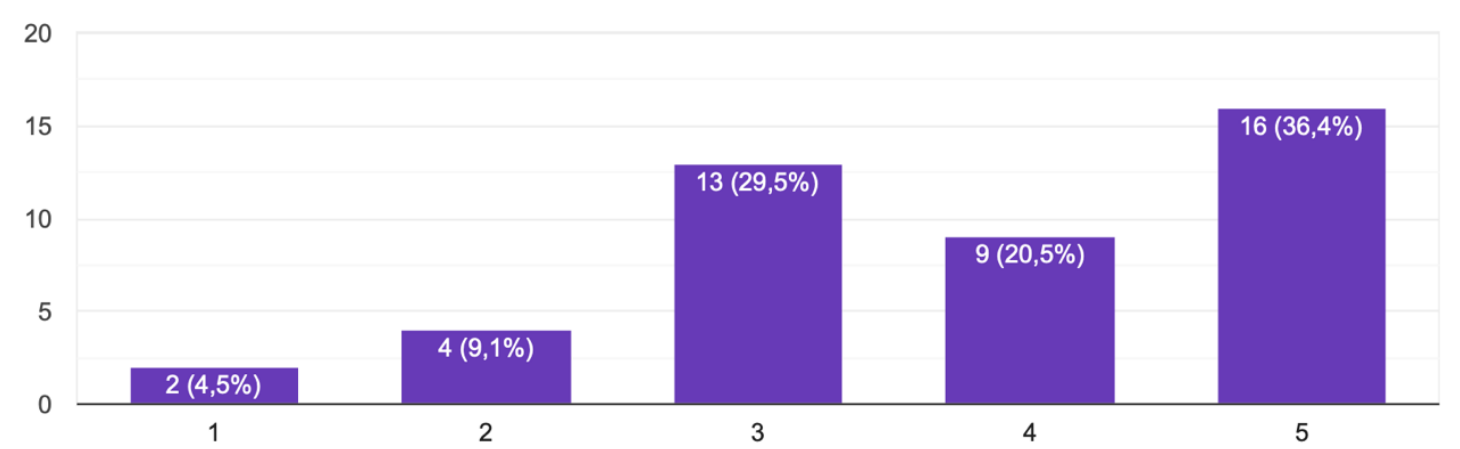


Figure 4. Information regarding University policy on plagiarism and the penalties thereof is available to the teaching staff.

Comparing data from before and after the pandemic, it was interesting to identify that more faculty suspected that an assignment had been written by a third party (76.2\% in Fall 2020) rather than before (73.8\% in Fall 2019). The survey also included questions about the forms of assignments that draw faculty members' attention and raise concerns for breaches of academic integrity. The three most common forms as pointed out by the respondents included "semester assignment which was submitted in digital form", pointed out by $54.8 \%$ of participants, followed by "online multiple-choice quiz" that received $26.2 \%$ and "weekly assignment which was submitted in digital form", selected by $11,9 \%$. Other forms of assignment that are considered less likely to be targets of academic dishonesty included "semester assignment which was submitted in printed form", "online quiz", and "weekly assignment which was submitted in printed form". There was also one incident of a Master's thesis. It is telling that only $2.4 \%$ of faculty responded that they were not aware of any attempt to breach academic integrity.

Most of the faculty (66.7\%) suspected a breach of academic integrity on an assignment due to inconsistency between the student's overall performance during the semester and their grade on the assignment. Software tools are also frequently triggering concerns about academic integrity as $52.4 \%$ of faculty testified to that effect. Other indicators include wrong references (14.3\%), issues with the focus of the submitted work that deviates from the topic of the assignment $(7.1 \%)$, and the examination of metadata for the file of the assignment, where a different author is revealed through the metadata, differing in name from the one under which the assignment was submitted.

\section{CONCLUSIVE REMARKS}

The survey among Greek faculty revealed a number of interesting points in relation to academic integrity. The first outcome is the fact that faculty admit that there are issues with academic integrity. This is important because in the work of Kokkinaki et al. the perceptions regarding plagiarism among faculty were different, with a significant percentage of faculty stating that there is no plagiarism in their courses/universities. Predominantly, faculty members consider plagiarism as the main issue regarding academic dishonesty. It is interesting to underline that faculty do not seem to recognize the terms 
describing other forms of academic dishonesty (for example, $45.2 \%$ of faculty do not recognize the term "ghostwriting", and $42.9 \%$ of them seem to ignore the term "contract cheating"). Evidence collected in this survey indicates that the coronavirus pandemic contributed positively to an increase in cases of academic dishonesty. This is mainly attributed to conducting many more assessment activities than before online, including the final examinations for the courses. It is useful to add that during that period, we saw many posts on social media soliciting domain experts to "assist" students with online exams and - in some cases - to sit in the exams in lieu of the students themselves. Faculty recognize text similarity software, regulation policies as well as educational actions as tools of determent. Overall, they recognize that each of these has limitations in their application, particularly in the aftermath of the pandemic.

\section{References}

Amzalag, M., Shapira, N. \& Dolev, N. (2021) Two Sides of the Coin: Lack of Academic Integrity in Exams During the Corona Pandemic, Students' and Lecturers' Perceptions. Journal of Academic Ethics. https://doi.org/10.1007/s10805-021-09413-5

Bashir, H., \& Bala, R. (2018). Development and validation of academic dishonesty scale (ADS): Presenting a multidimensional scale. International Journal of Instruction, 11(2), 57-74.

Birks, M., Mills, J., Allen, S., \& Tee, S. (2020). Managing the mutations: Academic misconduct Australia, New Zealand and the UK. International Journal for Educational Integrity.

Grira, J., \& Jaeck, L. (2019). Rationality and students' misconduct at university: Empirical evidence and policy implications. International Education Studies, 12(3), 10-23.

Harper, R., Bretag, T., \& Rundle, K. (2020). Detecting contract cheating: examining the role of assessment type. Higher Education Research \& Development, 1-16. 
Ives, B., Alama, M., Mosora, L. C., Mosora, M., Grosu-Radulescu, L., Clinciu, A. I., \& Dutu, A. (2017). Patterns and predictors of academic dishonesty in Romanian university students. Higher Education, 74(5), 815-831.

Yorke, J., Sefcik, L., Veeran-Colton, T. (2020) Contract cheating and blackmail: a risky business?. Studies in Higher Education 0:0, 1-14.

Khomami, N. (2017). Plan to crack down on websites selling essays to students announced. Higher Education. The Guardian. URL.

https://www.theguardian.com/education/2017/feb/21/plan-to-crack-down-onwebsites-selling-essays-to-students-announced

Krou, M.R., Fong, C.J., \& Hoff, M.A. (2020). Achievement motivation and academic dishonesty: A meta-analytic investigation. Educational Psychology Review, 1-32.

Marsh, S. (2017). Universities urged to block essay-mill sites in plagiarism crackdown. The Guardian: Higher Education https://www.theguardian.com/education/2017/oct/09/universities-urged-toblock-essay-mill-sites-in-plagiarism-crackdown.

Muhammad, A., Shaikh, A., Naveed, Q.N., \& Qureshi, M.R.N. (2020). Factors affecting academic integrity in e-learning of Saudi Arabian universities. An investigation using Delphi and AHP. IEEE Access, 8, 16259-16268.

Peytcheva-Forsyth, R., Aleksieva, L., Yovkova, B. (2018). The impact of technology on cheating and plagiarism in the assessment - The teachers' and students' perspectives. In AIP conference proceedings (Vol. 2048, No. 1, p. 020037). AIP Publishing LLC.

Dawson, P., Sutherland-Smith, W., Ricksen, M. (2020). Can software improve marker accuracy at detecting contract cheating? A pilot study of the Turnitin authorship investigate alpha. Assessment \& Evaluation in Higher Education 45:4, 473-482. 
Reynolds, R., \& Chu, S.K.W. (2020), Guest editorial. Information and Learning Sciences, Vol. 121 No. 5/6, pp. 233-239. Retrieved from: https:/ doi. org/ 10. 1108/ ILS- 05- 2020- 144

Rogerson, A. (2018). Detecting contract cheating in essay and report submissions: process, patterns, clues and conversations. In International Journal for Educational Integrity 13(10). Open: Springer.

Harper, R. Bretag, T. Rundle, K.. (2021). Detecting contract cheating: examining the role of assessment type. Higher Education Research \& Development 40:2, 263-278.

Comas-Forgas, R., Sureda-Negre, J., Morey-López, M. (2020). Spanish contract cheating website marketing through search engine advertisements. Assessment \& Evaluation in Higher Education 0:0, pages 1-13.

Sarwar, S., Idris, Z.M., \& Ali, S.M. (2018). Paid academic writing services: A perceptional study of business students. International Journal of Experiential Learning \& Case Studies, 3(1), 73-83. 